\title{
A!
}

This is an electronic reprint of the original article.

This reprint may differ from the original in pagination and typographic detail.

Hostikka, S.; Matala, A

\section{Pyrolysis Model for Predicting the Heat Release Rate of Birch Wood}

\section{Published in:}

Combustion Science and Technology

DOI:

$10.1080 / 00102202.2017 .1295959$

Published: 03/08/2017

Document Version

Peer reviewed version

Please cite the original version:

Hostikka, S., \& Matala, A. (2017). Pyrolysis Model for Predicting the Heat Release Rate of Birch Wood.

Combustion Science and Technology, 189(8), 1373-1393. https://doi.org/10.1080/00102202.2017.1295959

This material is protected by copyright and other intellectual property rights, and duplication or sale of all or part of any of the repository collections is not permitted, except that material may be duplicated by you for your research use or educational purposes in electronic or print form. You must obtain permission for any other use. Electronic or print copies may not be offered, whether for sale or otherwise to anyone who is not an authorised user. 
Pyrolysis model for predicting the heat release rate of birch wood

S. Hostikka* and A. Matala**

*) Aalto University, Espoo, Finland

**) VTT Technical Research Centre of Finland, Espoo, Finland

The numerical modelling of solid pyrolysis for fire simulations consists of three stages: specifying the reaction scheme and physical models, estimating the kinetic and thermal parameters from experimental data, and then solving the system using a computer. The interpretation of the experimental input parameters must be verified by reproducing the experimental conditions with the same model for which the parameters are being sought. In this work, we evaluated the performance of three previously proposed reaction schemes of wood pyrolysis in reproducing thermogravimetric experiments of birch wood, and determined the remaining model parameters from micro and bench scale calorimetric experiments. The predictive capability was tested by cone calorimeter experiments at different heat fluxes. The results indicate that the first-order single-step reaction scheme can provide equally good predictions for the heat release rate as the more complex schemes. The source of the thermal parameters - direct measurement or inverse modelling - did not have a great influence on the predictive capability.

Keywords: Pyrolysis modelling, Birch wood, Parameter estimation, Fire simulation

\section{Introduction}

The major challenge in the numerical simulations of unwanted fires is the need to predict the fuel inflow boundary condition. Fire spreading is a multi-physics, and often also multi-scale, problem. The production of flammable gases from the condensed phase materials involves heat transfer between the gas and condensed phases, thermal degradation (thermolysis) of the material, transport of the flammable gases, first 
Preprint, to appear in Combustion Science and Technology, 2017

within the condensed phase, and then in the gas phase, and finally combustion. The numerical models describing the condensed phase heat transfer and pyrolysis are called pyrolysis models. Many of the models were originally implemented for the needs of some other field than fire (Di Blasi, 2008). The earliest pyrolysis models for wood using Arrhenius kinetics were developed already on 1970s by Kung and his colleagues (Kung, 1972; Kung and Kalelkar, 1973). Atreya (1983) presented a comprehensive description of wood pyrolysis in the context of fire spread calculation, including one dimensional numerical model for pyrolysis. Parker (1986) implemented a simplified version of the model for the engineering analysis of wood burning rate under specified heat flux. Within the fire community, the current models have been implemented either as stand-alone models (Lautenberger and Fernandez-Pello, 2009; Stoliarov, 2010) or within the CFD-models for fire-induced flows (McGrattan et al., 2012; Chaos et al., 2011).

Ideally, the input parameters of the pyrolysis models could be determined by measuring the corresponding material properties. However, many of these parameters cannot be considered intrinsic properties of the material but effective, model-dependent parameters. For example, the definition of the heat of reaction of the thermal degradation reaction depends on the model formulation. In some models, the interphase heat transfer and the difference between the material's specific heat before and after the decomposition are explicitly taken into account in the heat conduction solution. In some, they have been lumped with the latent heat of polymer decomposition into a parameter called 'heat of reaction'. Also, it is very difficult to measure the material properties in temperatures where the material decomposes.

Due to the abovementioned difficulties, inverse methods are needed for determining the input parameters from small and bench scale experiments. Analytical methods for estimating the kinetic parameters from thermogravimetric experiments were developed already at 1960s (Friedman, 1964). Various versions of the so-called 'direct methods' have been developed in order to either simplify or generalize the reaction modelling. The direct methods have been supplemented by optimization methods that are used to estimate both reaction and thermal parameters from thermogravimetric (Chaos et al., 2011; Li et al., 2014; Ding et al., 2016) and bench scale experiments (Lautenberger et al., 2006). The modelling procedures for the heat 
Preprint, to appear in Combustion Science and Technology, 2017

release rate prediction follow the example of Atreya (1983), but the need to ensure the consistency of the experimental and numerical methods has become apparent. Like the numerical models themselves, the method of estimating their input parameters must be verified by simulating the experiments and trying to reproduce the measurement results.

The aim of this study was to develop a numerical model for a charring material of practical interest (birch) and to determine the input parameters using a number of available experimental techniques. We will verify the correct interpretation of the experimental results by simulating the experiments one by one, gradually increasing the completeness of the model. The modelling starts by selecting appropriate decomposition reaction schemes, continues with estimation of heats of reaction and combustion, and ends to the simulation of bench-scale burning experiment. The model validity is investigated by comparing experimental and predicted cone calorimeter results at different heat fluxes. The full-scale validation, which would be an important pre-requisite for practical applications, is not covered.

\section{Material and methods}

\section{Material}

The experiments were made using the samples of birch wood (Betula pendula). The dry density of the samples was $585 \pm 20 \mathrm{~kg} / \mathrm{m}^{3}$. When conditioned at $+21^{\circ} \mathrm{C}$ and $50 \%$ relative humidity, the moisture content of the material was $10 \pm 1 \%$ (wet basis).

To investigate the possibility to construct the reaction scheme using the information that is separately determined for the primary wood components cellulose, hemicellulose and lignin, commercially extracted powders of these components were used. Trade names and their assumed mass fractions are shown in Table 1. Xylan is known to originate from birch, but the wood species from which the cellulose and lignin were extracted are not known.

Table 1 
Preprint, to appear in Combustion Science and Technology, 2017

\section{Experimental}

Thermogravimetric analysis (TGA) of the birch samples were carried out using NETZSCH STA 449C equipment in Nitrogen atmosphere at heating rates, 2, 5, 10 and $20 \mathrm{~K} / \mathrm{min}$ from room temperature to 800 ${ }^{\circ} \mathrm{C}$. The sample mass was about $12 \mathrm{mg}$ and it was tested as a single particle, cut using a knife from a bigger piece of wood. For comparison, one experiment was carried out for a sample that was crushed with a hammer into small fragments, but the results were practically identical to those obtained with a rigid sample. The samples were dried before the experiment but they absorbed about 3.5 mass $\%$ moisture from air before the experiment started.

Differential scanning calorimetry (DSC) was used to determine the reaction enthalpy and the specific heat capacity. The amount of energy was scaled by the sample mass $\left(\Delta \mathrm{H}_{\mathrm{DSC}}=\Delta \mathrm{E} / \mathrm{m}_{0}\right)$. During the specific heat measurement, the heat flow was compared to the heat flow to a well-known reference sample. The heat of reaction, in turn, was measured without a reference by integrating time- $\Delta \mathrm{H}_{\mathrm{DSC}}$ curve over the temperature range of corresponding reaction, and by subtracting the integral of an assumed baseline curve over the same range. The experiments with grinded samples were made using Mettler Toledo Differential Scanning Calorimeter model DSC820 system STAR ${ }^{\mathrm{e}} \mathrm{SW} 8.10$, with expected precision of $\pm 7.5 \%$ for the absolute value and variance of $3 \%$. Open cups were used to minimize the effect of the secondary reactions between volatiles and char (Rath et al., 2003).

Pyrolysis combustion flow calorimetry (Lyon and Walters, 2004) was used to measure the heat release rate of the sample as a function of temperature. The experiments were made using the Micro-scale Combustion Calorimeter (MCC) apparatus, model MCC2 from Govmark Ltd. The heat release histories were integrated to calculate the material heat of combustion. Before the experiment, a block of birch was dried at $105{ }^{\circ} \mathrm{C}$ for several hours to measure the moisture content. The samples were then cut from the block with a knife, and pyrolysed in nitrogen atmosphere (ASTM D7309, Method A) by increasing the temperature from 75 ${ }^{\circ} \mathrm{C}$ to $800{ }^{\circ} \mathrm{C}$ at a constant rate, and the released pyrolysis gases were conducted to the combustor at $900{ }^{\circ} \mathrm{C}$ temperature and sufficient oxygen concentration to burn the gases completely. 
Preprint, to appear in Combustion Science and Technology, 2017

Small scale methods mentioned above only take into account the thermochemical degradation reactions, independent from the heat and mass transfer phenomena. To investigate the burning at larger scale, cone calorimeter (ISO 5660-1) experiments were carried out in air at 35, 50 and $75 \mathrm{~kW} / \mathrm{m}^{2}$ heat fluxes and using the spark ignitor. In two of the experiments at $50 \mathrm{~kW} / \mathrm{m}^{2}$, the sample size was $10 \mathrm{~cm} \times 10 \mathrm{~cm} \times 2.0 \mathrm{~cm}$. One of these tests was made with a steel frame and one without it. In the third test, the sample size smaller than what defined by the test standard $(6.0 \mathrm{~cm} \times 6.0 \mathrm{~cm} \times 2.0 \mathrm{~cm})$, and the sample was surrounded by mineral wool to insulate the sides of the sample. Samples were dried in a furnace at $105{ }^{\circ} \mathrm{C}$, wrapped to aluminium foil and insulated from the bottom by mineral wool. It is assumed that the samples were able to absorb some moisture between the removal from the furnace and the test. The mass loss rate of the sample was calculated by piecewise least squares fitting technique using finite interval method (Baroudi, 1993). Second order Hermite polynomials were fitted to the mass data, providing the mass-loss rate as the first derivative. The locations of the nodes (points of second derivative discontinuity) were chosen manually to accurately capture the sudden change of the mass loss rate at the moment of ignition.

The thermal conductivity was measured using the Transient Plane Source -method (Log \& Gustafsson, 1995) that is based on the simultaneous heat generation and temperature measurement in a flat sensor element placed between two samples with smooth surfaces. The measurements were done using a HotDisk TPS2500 S apparatus with a $6.4 \mathrm{~mm}$ diameter Kapton sensor. The measurement was made at room temperature. Birch samples were cut into $20 \mathrm{~mm}$ cubes and maintained at $20{ }^{\circ} \mathrm{C}$ temperature and $50 \%$ relative humidity before the measurements.

\section{Numerical}

The numerical simulations were performed using the pyrolysis solver of the Fire Dynamics Simulator software (McGrattan et al. 2012), version 6.3.2. In the gas phase, FDS solves the low-Mach number form of the Navier-Stokes equations and applies LES for turbulence. Thermal radiation is calculated using a Finite Volume Method for grey gas. The gas phase combustion reactions are assumed to be mixingcontrolled. The solid phase pyrolysis solver obtains its thermal boundary condition from the CFD solver 
and can provide both thermal and mass flux boundary conditions to the CFD solver, thus implementing a two-way coupling between the gas and solid phases. Independent pyrolysis solutions are computed for all CFD wall boundary cells associated with conductive and reactive surfaces. The same computer code can therefore be used both as a stand-alone pyrolysis solver to simulate small and bench scale material behaviour and to investigate fully coupled flame spread phenomenon by considering the spatially varying boundary conditions.

The pyrolysis solver assumes that the solids can undergo simultaneous reactions but the resulting volatile gases are released instantaneously to the gas phase without any internal interphase heat exchange or condensation. Heat conduction is calculated using a one-dimensional heat conduction equation

$$
\rho_{s} c_{s} \frac{\partial T}{\partial t}=\frac{\partial}{\partial x}\left(k_{s} \frac{\partial T}{\partial x}\right)+\&_{s}^{\prime \prime}
$$

where $\rho_{\mathrm{s}}$ is the density of the material mixture, and the co-ordinate $x$ is the perpendicular distance from the solid-gas boundary, being zero at the material surface. The boundary condition on the front surface of the material is

$$
-k_{s} \frac{\partial T}{\partial x}(0, t)=h\left[T_{g}-T_{s}(0, t)\right]+\varepsilon\left[\mathbb{\psi}_{r}-\sigma T_{s}(0, t)^{4}\right]
$$

where $T_{g}$ is the gas temperature of the nearest gas-phase grid cell, $h$ is the convective heat transfer coefficient, $\varepsilon$ is the spectrally averaged emissivity, and $\$$ is the incident radiative heat flux. Similar condition is used on the back-side of the material.

The conductivity and volumetric heat capacity of the solid are defined as

$$
\begin{aligned}
& k_{s}(x)=\sum_{\alpha=1}^{N_{m}} X_{\alpha}(x) k_{s, \alpha} \\
& \left(\rho_{s} c_{s}\right)(x)=\sum_{\alpha=1}^{N_{m}} \rho_{s, \alpha} c_{s, \alpha}
\end{aligned}
$$


where $N_{m}$ is the number of material components forming the solid, $X_{\alpha}$ is the volume fraction of component $\alpha$, and $\rho_{\mathrm{s}, \alpha}$ is the component mass concentration

$$
\rho_{s, \alpha}=Y_{\alpha} \rho_{s}
$$

Here $Y_{\alpha}$ is the mass fraction of component $\alpha$. The solid density is the sum of the component mass concentrations and the volume fractions are calculated as

$$
X_{\alpha}=\frac{\rho_{s, \alpha}}{\rho_{\alpha}} / \sum_{\alpha^{\prime}=1}^{N_{m}} \frac{\rho_{s, \alpha^{\prime}}}{\rho_{\alpha^{\prime}}}
$$

where $\rho_{\alpha}$ is the true density of material $\alpha$ in its pure form. Multi-component solids are defined by specifying the mass fractions $Y_{\alpha}$, and densities $\rho_{\alpha}$, of the individual components of the composite.

The chemical source term is

$$
\mathbb{q}_{S}^{\prime \prime}(x)=-\rho_{s}(0) \sum_{\alpha=1}^{N_{m}} \sum_{\beta=1}^{N_{r, \alpha}} r_{\alpha \beta}(x) H_{r, \alpha \beta}
$$

where $r_{\alpha \beta}$ is the reaction rate for the $\beta$ 'th reaction of the $\alpha^{\prime}$ th material component and $H_{r, \alpha \beta}$ is the corresponding heat of reaction. The reaction rates are calculated using the Arrhenius functions

$$
r_{\alpha \beta}(x)=\left(\frac{\rho_{s, \alpha}(x)}{\rho_{s}(0)}\right)^{n_{\alpha \beta}} A_{\alpha \beta} \exp \left(-\frac{E_{\alpha \beta}}{R T_{S}(x)}\right)
$$

Note that although the normalization of the instantaneous mass concentration in the kinetic model function is conventionally arbitrary, it is different from the models of Lautenberger and Fernandez-Pello (2009) and Stoliarov et al. (2010).

The local density of material component $\alpha$ evolves in time according to the solid phase species conservation equation 


$$
\frac{\partial}{\partial t}\left(\frac{\rho_{s, \alpha}(x)}{\rho_{s}(0)}\right)=-\sum_{\beta=1}^{N_{r, \alpha}} r_{\alpha \beta}(x)+S_{\alpha}(x)
$$

where $S_{\alpha}$ is the production rate of material component $\alpha$ as a result of the reactions of the other components

$$
S_{\alpha}(x)=\sum_{\alpha^{\prime}=1}^{N_{m}} \sum_{\beta=1}^{N_{r, \alpha^{\prime}}} v_{\alpha, \alpha^{\prime} \beta} r_{\alpha^{\prime} \beta}(x)
$$

In the above equation, the products of the material $\alpha$ yields and the reaction rates are summed over all the material components and all the reactions of each material. The mass flux of a volatile reaction product, $\gamma$, out of the material is calculated by integrating the volumetric production rate over the material thickness

$$
n \&=\int_{0}^{L} \rho_{s}(0) \sum_{\alpha=1}^{N_{m}} \sum_{\beta=1}^{N_{r, \alpha}} v_{\gamma, \alpha \beta} r_{\alpha \beta}(x) d x
$$

Due to the assumptions, the heat of reaction $H_{r, \alpha \beta}$ must be considered as an effective model parameter describing the difference between the enthalpies of the post- and pre-reaction stages of the material. In addition to the (latent) heat of thermal degradation, it takes into account the difference between the specific heats of the solid and gaseous materials. Also, the heat transfer between solid material and the internal gas flow can only be modelled through this parameter because the internal gas transport is not explicitly simulated.

Equation (1) is solved numerically by finite differences, using implicit Crank-Nicholson method for time integration and linearized radiation boundary conditions to avoid iterations. In the linearized boundary condition, the fourth power of the surface temperature at new time step $T(0, t+\Delta t)$ is expanded around the previous-time step value $T(0, t)$

$$
T_{S}(0, t+\Delta t)^{4} \approx\left[T_{S}(0, t)\right]^{4}+4\left[T_{S}(0, t)\right]^{3}\left[T_{S}(0, t+\Delta t)-T_{S}(0, t)\right]
$$

which leads to the following approximation for the radiative flux (last term of Eq. 2) 


$$
\Phi-\sigma\left(T_{S}(0, t+\Delta t)\right)^{4} \approx \not \mathbb{W}-\sigma\left[T_{S}(0, t)\right]^{4}-4 \sigma\left[T_{S}(0, t)\right]^{3}\left[T_{S}(0, t+\Delta t)-T_{S}(0, t)\right]
$$

Reaction terms are calculated explicitly using the temperature and the material concentrations from the previous time step. In the simulations of the small scale experiments, the sample with an adiabatic backing was made very small ( $1 \mu \mathrm{m}$ layer) to ensure thermal equilibrium with the virtual 'furnace', and thus only a single solid phase cell is required for the computation. The time step of the small scale simulations was set to $0.01 \mathrm{~s}$.

In cone calorimeter simulations, the spatial resolution in the solid was $0.4 \mathrm{~mm}$ and the time step was set initially to $0.2 \mathrm{~s}$. During the gas phase flaming, the hydrodynamic solver reduced the time step down to $0.01 \mathrm{~s}$. The heat conduction to the mineral wool below the sample was computed by extending the numerical mesh to the wool. The thermal properties of the mineral wool were $\rho_{\mathrm{s}}=64 \mathrm{~kg} \cdot \mathrm{m}^{-3}, c_{\mathrm{s}}=0.7 \mathrm{~kJ} \cdot(\mathrm{kg} \cdot \mathrm{K})^{-1}, k_{\mathrm{s}}$ $=\{0.034,0.08,0.19\} \mathrm{W} \cdot(\mathrm{m} \cdot \mathrm{K})^{-1}$ for temperatures $20^{\circ} \mathrm{C}, 260{ }^{\circ} \mathrm{C}$ and $538{ }^{\circ} \mathrm{C}$.

The small scale simulations took typically less than $5 \mathrm{~s}$ on a single core of a $1.9 \mathrm{GHz}$ Pentium processor, and the $800 \mathrm{~s}$ real-time simulations of the cone calorimeter experiments took 100-300 s on a quad-core 1.9 GHz processor with 8 GB RAM.

\section{Reaction schemes}

Three different reaction schemes were used for modelling the birch pyrolysis (Figure 1). The simplest possible approach for modelling the wood pyrolysis is a single-step reaction that converts virgin wood to char and flammable gas. Assuming $n_{\mathrm{s}, \alpha}=1$ allows us to calculate the pre-exponential factor and activation energy analytically. In the second scheme, the reacting wood is constructed from the three main components that decompose independently. Grønli et al. (2002) used first-order reactions and determined the kinetic parameters by curve fitting. In this work, we also allow non-unity reaction orders and extend the model by considering the moisture evaporation. A similar approach was recently used Li et al. (2014) and Ding et al. (2016) to predict the pyrolysis kinetics of Medium-Density Fibreboard and beech, respectively. In both works, the kinetic parameters were obtained from TGA data by optimization. 


\section{Single-step scheme}

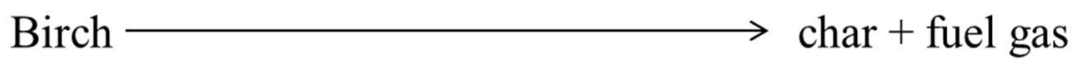

Modified Gronli scheme

$$
\text { Birch }=\left\{\begin{array}{lll}
\text { cellulose } & \longrightarrow \text { char }_{\mathrm{C}}+\text { fuel gas } \\
\text { hemicellulose } & \text { char }_{\mathrm{HC}}+\text { fuel gas } \\
\text { lignin } & \text { char }_{\mathrm{L}}+\text { fuel gas } \\
\text { water } & \text { water vapour }
\end{array}\right.
$$

$$
\begin{aligned}
& \text { Modified Broido-Shafizadeh scheme } \\
& \text { Birch }= \begin{cases}\text { cellulose and hemicellulose } & \left\{\begin{array}{l}
\text { a) char }+ \text { fuel gas } \\
\text { b) tar } \longrightarrow\left(+\mathrm{O}_{2}\right) \text { fuel gas } \\
\text { lignin } \longrightarrow
\end{array}\right. \\
\text { char }+ \text { fuel gas } \\
\text { water } \longrightarrow \text { water vapour }\end{cases}
\end{aligned}
$$

Figure 1 Reaction schemes.

Di Blasi (1998) used the Broido-Shafizadeh reaction scheme for modelling lignocellulosic materials, since the cellulose and hemicellulose together form about $75 \%$ of the wood material. The scheme consists of three reactions: Solid wood is first converted to active solid, which then undergoes further degradation depending on the temperature and oxygen concentration. In lower temperatures intermolecular dehydration is dominating, yielding char and gas. In high temperatures depolymerization dominates, producing tar which in the presence of air will combust with flame. In this work, we modify the scheme by ignoring the reactions that do not cause any mass loss and thus cannot be observed in the TGA, and by including the moisture evaporation and the lignin decomposition (Figure 1).

\section{Parameter estimation}

The kinetic parameters were estimated using two techniques: direct analytical method and curve fitting by genetic algorithm (GA). The analytical method (Lyon et al., 2011) assumes that the reaction order $n_{s, \alpha \beta}=1$ and gives the kinetic parameters $A_{\alpha \beta}$ and $E_{\alpha \beta}$ in eq. (7) as 


$$
A_{\alpha 1}=\frac{e r_{p, \alpha}}{Y_{s, \alpha}(0)} \exp \left(-\frac{E_{\alpha 1}}{R T_{p, i}}\right) ; E_{\alpha 1}=\frac{e r_{p, \alpha}}{Y_{s, \alpha}(0)} \frac{R T_{p, i}^{2}}{T^{\mathcal{\alpha}}}
$$

where $r_{\mathrm{p}, \mathrm{i}} / Y_{\mathrm{s}, \alpha}(0)$ and $T_{\mathrm{p}, \mathrm{i}}$ and the peak reaction rate and its temperature, respectively. $Y_{\mathrm{s}, \alpha}(0)$ is the mass

fraction of the component $\alpha$ in the initial mixture, and $\alpha_{i s}$ the heating rate. The estimation was carried out using the program implementation of McGrattan et al. (2015).

Genetic algorithm is an optimization method that can be used for fitting almost any kind of model to experimental data (Matala, 2013). The estimation bounds, the most important parameters guiding the process, were defined using available experimental information about the typical values. If more than one parameter converged to the estimation bound, the estimation bounds were extended and the optimization was repeated. The kinetic parameters of the complex reaction schemes were estimated with GA from the TGA data. The remaining parameters were either measured, fitted manually to the other small-scale data, or estimated from the cone calorimeter results using GA.

\section{Results and discussion}

\section{Evaluation of the reaction schemes using TGA data}

Figure 2 shows the results of the thermogravimetric experiments for mass (TGA) and mass loss rate (MLR). The initial wood mass fractions, char yields, peak MLR values and the corresponding temperatures are listed in Table 2. The peak temperatures are shown in the figure with vertical straight lines. The pyrolysis reactions start around $250{ }^{\circ} \mathrm{C}$, have a shoulder between 280 and $310{ }^{\circ} \mathrm{C}$ and continue with one or more overlapping reactions until the final peak between 340 and $380{ }^{\circ} \mathrm{C}$. The small mass loss around $100{ }^{\circ} \mathrm{C}$ corresponds to the evaporating water. The temperature results are in line with the birch data from Grønli et al. (2002) (obtained at $5 \mathrm{~K} / \mathrm{min}$ heating rate), reporting onset, shoulder and peak temperatures to be $240{ }^{\circ} \mathrm{C}$, $295{ }^{\circ} \mathrm{C}$ and $353{ }^{\circ} \mathrm{C}$, respectively. However, there are some differences in the relative magnitudes of the shoulder and peak decomposition peaks. In our experiment at $5 \mathrm{~K} / \mathrm{min}$, the MLR (dry basis) at the shoulder and peak were $0.41 \times 10^{-3} \mathrm{~s}^{-1}$ and $1.2 \times 10^{-3} \mathrm{~s}^{-1}$, while the corresponding values from Grønli et al. (2002) 
Preprint, to appear in Combustion Science and Technology, 2017

were $0.47 \times 10^{-3} \mathrm{~s}^{-1}$ and $0.98 \times 10^{-3} \mathrm{~s}^{-1}$. This difference may be caused by the different fractions of wood primary components.
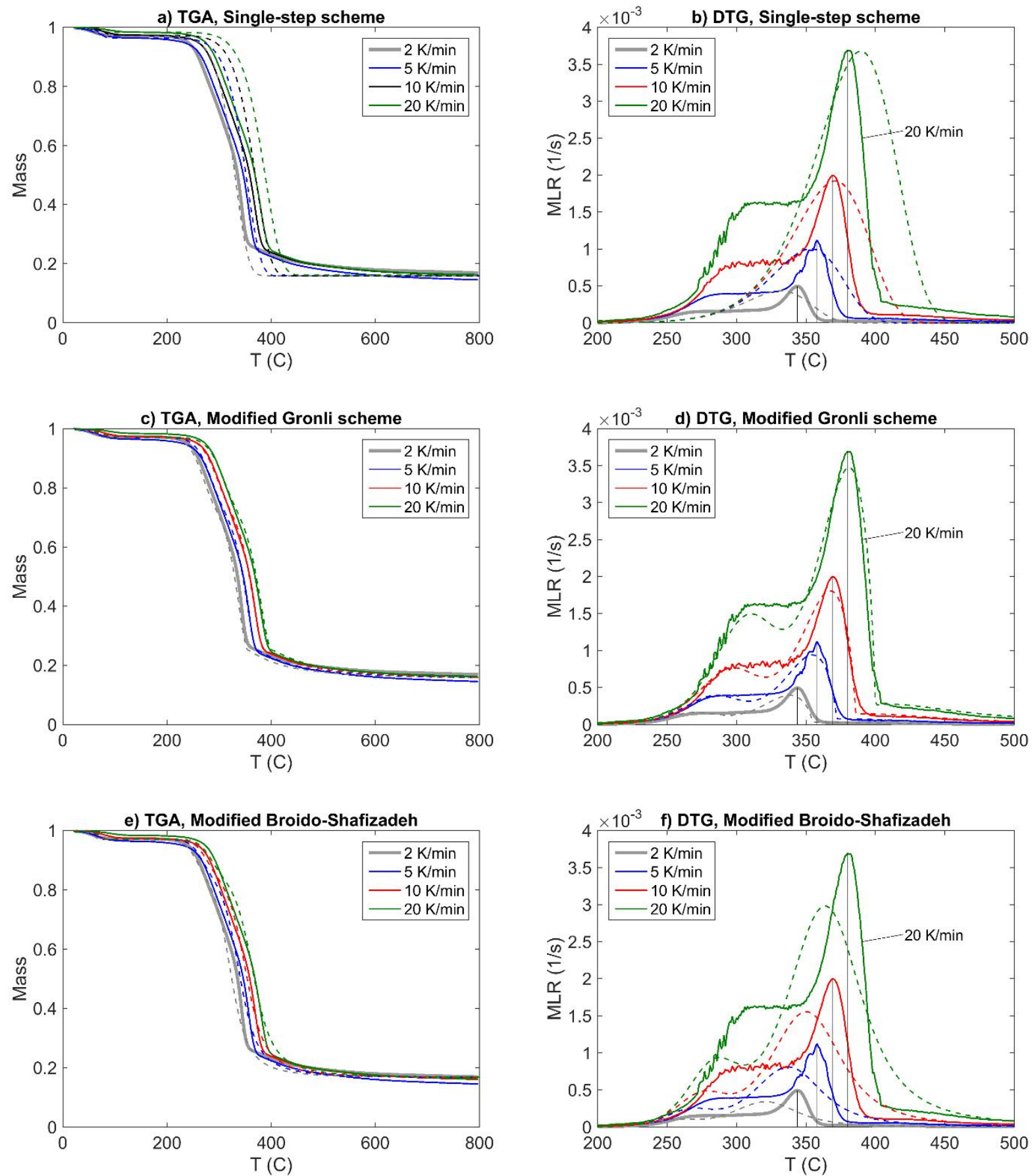

Figure 2. TGA (left column) and DTG (right column) results for experiments (solid lines) and simulations (dashed lines) with single-step scheme (a-b), modified Gronli scheme (c-d), and modified BroidoShafizadeh scheme (e-f). 
Preprint, to appear in Combustion Science and Technology, 2017

Table 2.

The parameters of the first-order single-step reactions were estimated separately for each heating rate from the TGA data using Eq. (13). The heating-rate specific kinetic coefficients (Table 2) were then generalized for arbitrary heating rates by taking an arithmetic average of the activation energies, and then finding a corresponding $A_{\alpha 1}$ value from the straight line fitted to the four data points $\operatorname{in} \ln (A)-E$ space. The resulting coefficients are shown on the last row of Table 2, and the resulting predictions in Figure $2 \mathrm{a}-\mathrm{b}$. The peak temperatures are correctly reproduced but the initiation around $250{ }^{\circ} \mathrm{C}$ is not captured by the model, as the overall reaction ranges are shifted towards high temperatures. The model seems to exaggerate the influence of the heating rate on the reaction temperatures.

For the application of the modified Grønli scheme, we first investigated if the kinetic parameters of the cellulose, hemicellulose and lignin could be estimated independently from the TGA curves of their extracted forms. The TGA tests were carried out for the powder-form samples, resulting in relative mass loss of $92 \%$ for cellulose, $79 \%$ for hemicellulose and $52 \%$ for lignin. Figure 3 shows the MLR curves of the birch sample and the three primary components at $5 \mathrm{~K} / \mathrm{min}$ heating rate. A weighted sum of the individual components was then calculated using the assumed mass fractions in Table 1 as weights. The sum of the components (dashed line) agrees with the birch MLR between $200{ }^{\circ} \mathrm{C}$ and $300{ }^{\circ} \mathrm{C}$ where the mass loss is mainly from Xylan and lignin. The peak of the sum curve, corresponding to the cellulose decomposition, is at $330{ }^{\circ} \mathrm{C}$ while the peak of the wood pyrolysis curve is observed at $359{ }^{\circ} \mathrm{C}$. This can be caused by different chemical compositions and physical forms (powder vs. solid) of the samples. It is important to note that the cellulose and lignin extracts were commercial materials with unknown origin species. In any case, building an engineering model from the independent reactions of the measured primary components is not considered a viable option. 


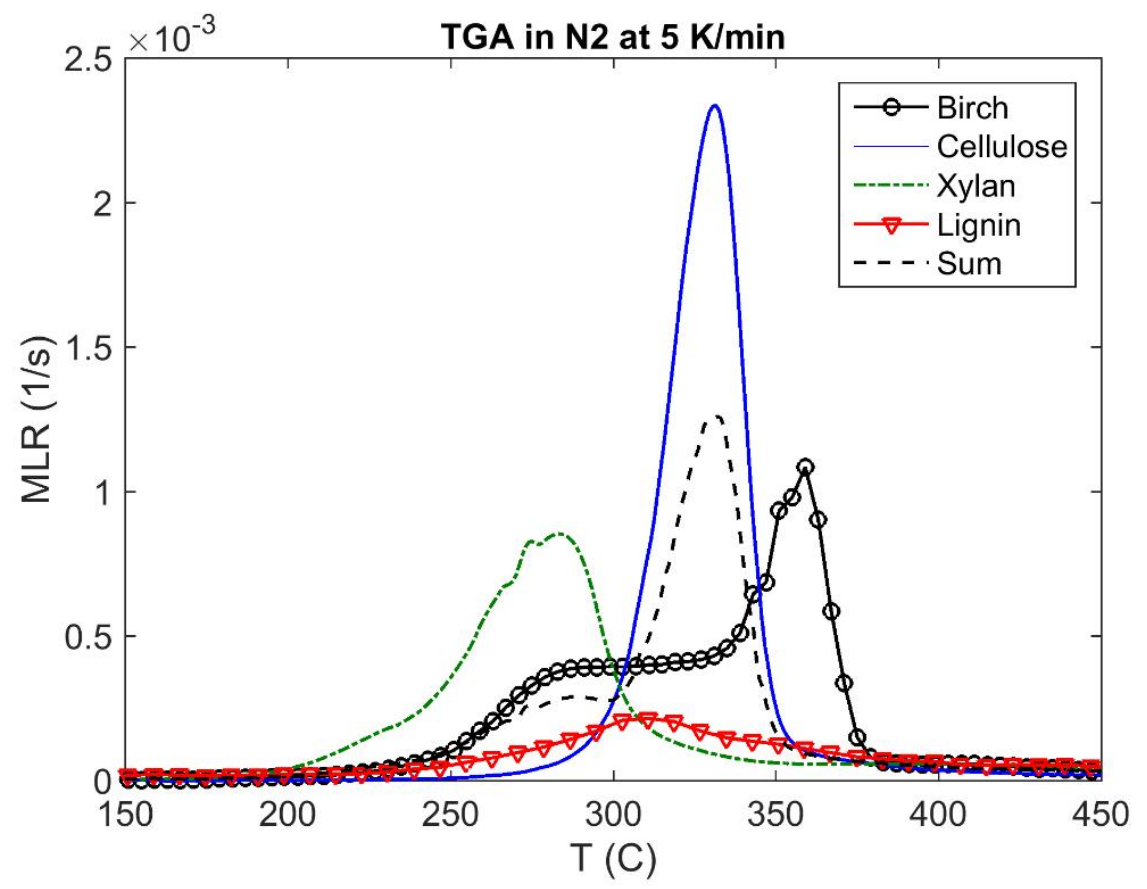

Figure 3. TGA mass loss rates for birch, wood primary components and a weighted sum of the components.

Next, the kinetic parameters for the modified Grønli scheme were estimated using GA that fitted a weighted sum of component mass loss rates to the birch TGA data. The assumed mass fractions were those in Table 1. The estimation bounds were chosen to direct the reactions to take place in the correct order (hemicellulose before cellulose), allowing overlapping and simultaneous reactions though. The bounds for the fuel yields were based on the TGA results of the individual components. The GA process converged in few tens of iterations. The estimation bounds and the estimated parameters are shown in Table 3, and the simulated TGA curves in Figure $2 \mathrm{c}$-d. The model reproduces three important aspects of the experimental MLR curve: (1) the shoulder of the reaction, i.e. the initiation of pyrolysis, (2) the location and magnitude of the cellulose degradation peaks, and (3) the high-temperature tail. The simulations show a slight dip in the range 300$350{ }^{\circ} \mathrm{C}$ while the measured MLR between the shoulder and the cellulose peak is almost constant in this range. This can indicate that the real reactions are not as distinct and independent as the model assumes. The real hemicellulose may contain a range of different polymers, thus exhibiting thermal decomposition 
Preprint, to appear in Combustion Science and Technology, 2017

over a wider temperature range than what is observed for extracted Xylan. The chemical interactions between the components cannot be ruled out either.

Table 3

In the Grønli scheme results, the high-temperature tail results from the slow decomposition of lignin, as indicated by the high value of the reaction order. In reality, all the individual components continue their decomposition in the $400-450{ }^{\circ} \mathrm{C}$ range, but the GA has allocated all the mass loss to the lignin decomposition.

The kinetic parameters of the modified Broido-Shafizadeh were also estimated with GA, using the prior information about the temperature ranges to define the estimation bounds. The GA algorithm converged in 58 iterations, although the estimation results remained relatively unchanged after 30 iterations. The estimation bounds and the resulting parameters are shown in Table 4, and the model predictions in Figure 2 e-f. This multi-step model is shown to reproduce the shoulder-peak form of the MLR curve better than the single-step model, but the overall quantitative agreement is not as good as with the modified Grønli scheme. Merging the cellulose and hemicellulose into a one component does not seem justified due to their different degradation temperatures (Figure 3). In the absence of the separate cellulose and hemicellulose components, the genetic algorithm tries to reproduce the shoulder of the reaction using the lignin decomposition. This result illustrates that the assumed reaction scheme must be based on the correct physical behaviour.

Table 4

\section{Heat flow (DSC)}

The specific heat capacities were measured over the temperature ranges where the material did not undergo degradation reactions. The results are reported as averages of three replicate measurements. In addition to the fresh wood, the specific heat capacity was also measured for char that was produced by pyrolyzing the birch wood samples at $550{ }^{\circ} \mathrm{C}$ in inert atmosphere of the DSC furnace. The results are shown in Table 5. 
Preprint, to appear in Combustion Science and Technology, 2017

The specific heat increases with temperature for both virgin wood and char, but the values of the char are significantly lower than those of the virgin wood. Luostarinen and Verkasalo (2000) have made a similar observation. In general, the measured values are slightly lower than the previously reported values (Harada et al., 1998): $c_{\mathrm{s}}\left(20^{\circ} \mathrm{C}\right)=1.25 \mathrm{~kJ} \cdot(\mathrm{kg} \cdot \mathrm{K})^{-1}$ and $c_{\mathrm{s}}\left(100{ }^{\circ} \mathrm{C}\right)=1.45 \mathrm{~kJ} \cdot(\mathrm{kg} \cdot \mathrm{K})^{-1}$.

Table 5

Three replicate measurements of the reaction enthalpy were performed with DSC. The results are shown in Figure 4. As the enthalpy measurement is performed without a reference sample, only the relative changes can be quantified. Therefore, an arbitrary offset was added to each curve to enable their comparison. The apparent heat of reaction is endothermic. In their experiments for spruce and beech woods, Rath et al. (2003) observed a secondary exothermic stage following the primary pyrolysis, i.e. at $380{ }^{\circ} \mathrm{C}$ and above. Due to the uncertainties in the baseline definition, we could not identify nor quantify such a stage from the DSC measurements.

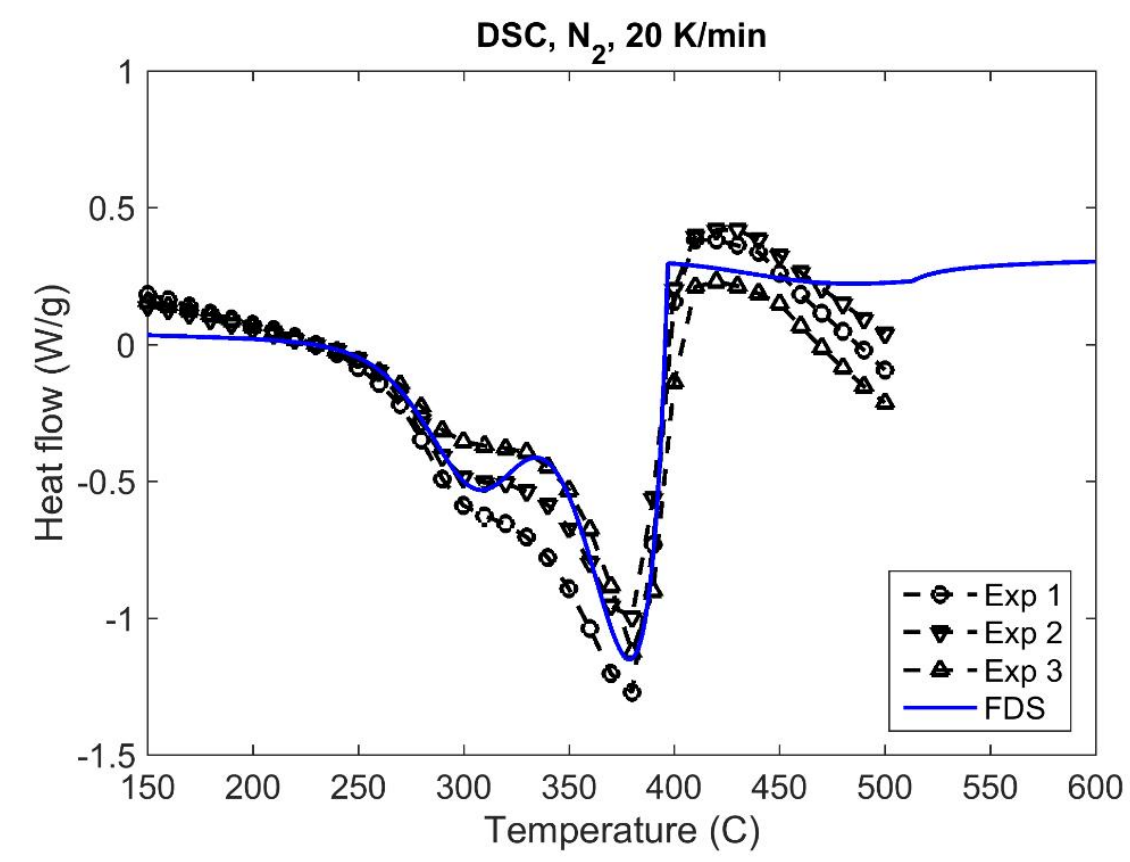

Figure 4. DSC measurement and simulation of the reaction enthalpy for birch pyrolysis. Exothermic direction is upwards. 
In theory, the heat of reaction for a material component $\alpha$ in Equation 6 can be calculated by dividing the normalized DSC integral $\Delta \mathrm{H}_{\mathrm{DSC}}$ with the component mass fraction $Y_{\alpha}$

$$
\Delta H_{r, \alpha}=\frac{\Delta H_{D S C}}{Y_{\alpha}}=\frac{\Delta E}{m_{0} Y_{\alpha}}
$$

Here we have assumed that compound $\alpha$ is consumed completely in the reaction. If the observed reaction consists of several overlapping reactions, the same heat of reaction must be used for all of them. Calculating the area integrals $\Delta H_{D S C}$ turned out to be sensitive to the choices of the reaction start and end temperatures, as well as the shape of the baseline curve. As large as $30 \%$ variations were obtained between individual, visually well-justified assumptions for the baseline. Therefore, it seemed more reliable to estimate $\Delta H_{r, \alpha}$ by simulation-based estimation using the modified Grønli scheme (Figure 4). Good agreement was found with $H_{\mathrm{r}}=400 \mathrm{~kJ} / \mathrm{kg}$ (endothermic). The same value was used for all the wood components. The shape of the predicted DSC curve could be adjusted further by specifying different values for the components, but this would not be justified considering the apparent experimental and modelling uncertainties.

\section{Thermal conductivity (Hot disk)}

The mean of ten measurements in direction perpendicular to the grain was $0.216 \mathrm{~W} \cdot(\mathrm{m} \cdot \mathrm{K})^{-1}$ with a standard deviation of $0.001 \mathrm{~W} \cdot(\mathrm{m} \cdot \mathrm{K})^{-1}$. In the grain direction, the measured mean value was $0.30 \mathrm{~W} \cdot(\mathrm{m} \cdot \mathrm{K})^{-1}$ with a standard deviation of $0.003 \mathrm{~W} \cdot(\mathrm{m} \cdot \mathrm{K})^{-1}$.

For the conductivity of birch wood, values in the range $0.18-0.21 \mathrm{~W} \cdot(\mathrm{m} \cdot \mathrm{K})^{-1}$ have been reported in room temperature and $0.21-0.25 \mathrm{~W} \cdot(\mathrm{m} \cdot \mathrm{K})^{-1}$ at $100{ }^{\circ} \mathrm{C}$ (Suleiman et al., 1999). For the thermal conductivity of birch char, values 0.08-0.1 W. $(\mathrm{m} \cdot \mathrm{K})^{-1}$ were reported by Hankalin et al. (2009). The wood thermal conductivity along the grains is typically 1.5-2.8 times higher than the perpendicular value, and the effective conductivity has been found to increase with increasing moisture content (Simpson and TenWolde, 1999). 
Preprint, to appear in Combustion Science and Technology, 2017

\section{Heat release (MCC)}

MCC experiments were performed with 2.5-6.6 mg samples. The nominal heating rates were 20 and 60 $\mathrm{K} / \mathrm{min}$, but when the furnace temperature log of the apparatus was examined, the true heating rates were found to be 33 and $85 \mathrm{~K} / \mathrm{min}$, respectively.

The integrated dry birch results of the three repeated tests are shown in Table 6 . The total mass losses are slightly higher than in TGA, and the peak temperature at $20 \mathrm{~K} / \mathrm{min}$ heating rate is lower than the corresponding value in TGA. The reasons for these differences are presently unknown. Smaller sample sizes are known to correspond to lower peak temperatures (Stenseng et al., 2001) but our MCC results with sample sizes of $2 \ldots 6 \mathrm{mg}$ do not support this hypothesis. The peak temperature difference, in particular, is peculiar because the higher true heating rate should result in higher peak temperature.

\section{Table 6}

The MCC experiments were simulated using the modified Grønli reaction scheme and three different sets of heats of combustion. The measured and simulated heat release rates in MCC experiments are plotted in Figure 5. To enable a direct visual comparison of the results despite the different degradation temperatures, the temperature axes have been normalized using the peak temperatures.

The solid line in Figure 5 corresponds to the simulations where an average heat of combustion $14.35 \mathrm{MJ} / \mathrm{kg}$ was used for all three wood components. The simulated HRR is lower than measured except for the cellulose pyrolysis peak of the $60 \mathrm{~K} / \mathrm{min}$ heating rate. The discrepancy between the simulated and experimental results is due to the different yields of gaseous fuel. 

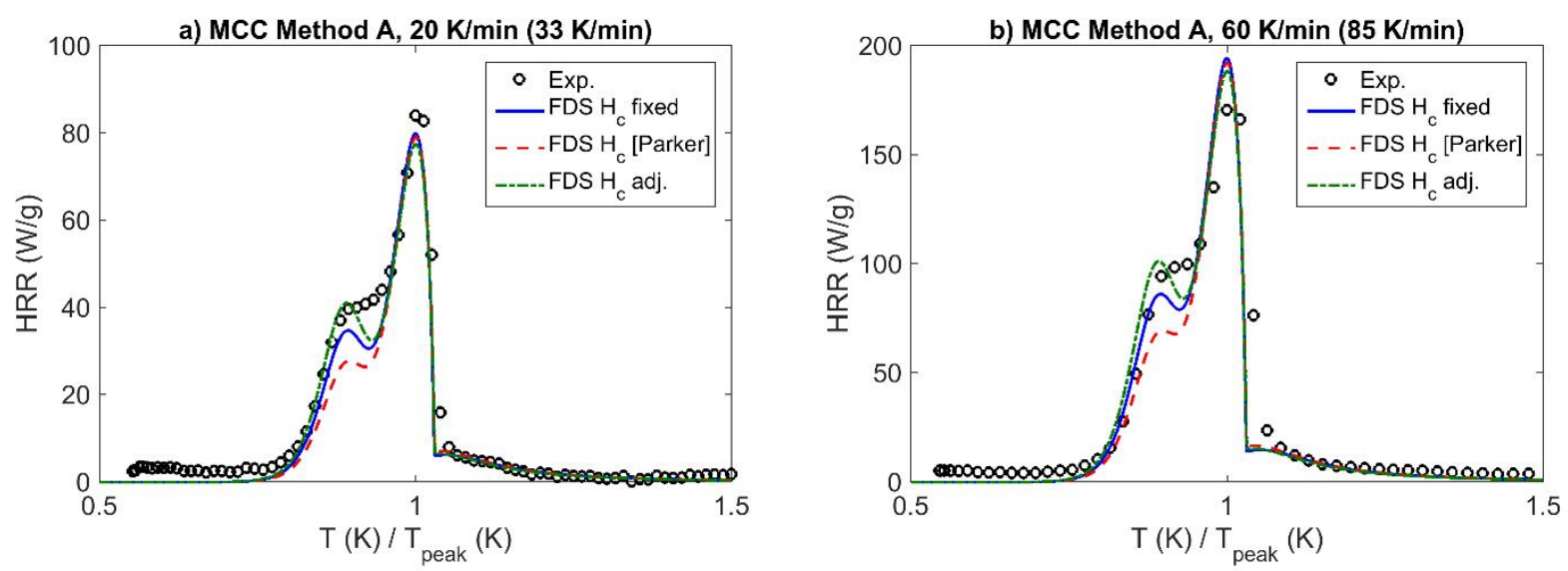

Figure 5. MCC results of birch at $33 \mathrm{~K} / \mathrm{min}$ (left) and $85 \mathrm{~K} / \mathrm{min}$ (right) heating rates. Experimental data with circles and simulated with lines. See text for the explanation of simulations.

In his model for Douglas fir pyrolysis, Parker (1989) used the following values for the volatile heats of combustion of cellulose, hemicellulose and lignin: $13.8 \mathrm{MJ} / \mathrm{kg}, 10.7 \mathrm{MJ} / \mathrm{kg}$, and $14.7 \mathrm{MJ} / \mathrm{kg}$, respectively. The calculation results with these values are shown with dashed lines in Figure 5. The results are similar to those obtained with $H_{\mathrm{c}, \alpha}=14.35 \mathrm{MJ} / \mathrm{kg}$ but the underestimation of HRR during the hemicellulose decomposition stage is now even greater.

As a third option, an optimized set of component heats of combustion (dash-dot line of Figure 5) was developed by first fitting the cellulose peak, then the hemicellulose shoulder, and finally choosing a value for lignin that produces a correct weighted average. The resulting values were $13.5 \mathrm{MJ} / \mathrm{kg}$ for cellulose, 17.0 MJ/kg for hemicellulose and 13.4 MJ/kg for lignin.

Despite the quantitative differences in reaction temperatures, the modified Grønli scheme was able to reproduce the temperature dependence of the HRR when the component specific heats of combustion were set appropriately. The local differences between the experimental and model results were less than $21 \%$ if these values were optimized, and less than $26 \%$ the averaged value was used. 


\section{Ignition and burning rate (Cone calorimeter)}

The cone calorimeter simulations were carried out with $5.0 \mathrm{~cm}$ gas phase resolution. A mesh sensitivity study was performed to investigate the capability of such a model to capture the flame's contribution to the heat exposure. In the simulations of the experiments with $50 \mathrm{~kW} / \mathrm{m}^{2}$ external heat flux, the flame heat flux varied between 4 and $12 \mathrm{~kW} / \mathrm{m}^{2}$ and increase to range $10-15 \mathrm{~kW} / \mathrm{m}^{2}$ when the gas phase resolution was refined to $1.0 \mathrm{~cm}$. However, the predicted HRR changed only a few percent for two reasons: First, sufficient emission of thermal radiation from the flame was ensured by prescribing a constant fraction of the local volumetric HRR that was assigned to the emission source term of the radiative transport equation. With an assumption of $30 \%$ radiative fraction, flame heat fluxes of correct order of magnitude were observed at the sample surface. As a sensitivity test, it was found that reducing the radiative fraction to $25 \%$ did not change the burning rates significantly. The second reason was the relatively high external heat flux that dominated the heat transfer to the sample over the predicted flame heat fluxes. The difference between the two resolutions is less than $10 \%$ in total incident flux, and thus even less in the net heat flux.

The unknown model parameters were estimated from the cone calorimeter experiments at $50 \mathrm{~kW} / \mathrm{m}^{2}$ heat flux. Two different models of the cone calorimeter were created for each of the three reaction schemes: In the first model, measured values $\left(\rho_{\mathrm{s}}=600 \mathrm{~kg} / \mathrm{m}^{3}, k_{\mathrm{s}}\left(20^{\circ} \mathrm{C}\right)=0.216 \mathrm{~W} / \mathrm{K} \cdot \mathrm{m}, H_{\mathrm{r}, \alpha}=400 \mathrm{~kJ} / \mathrm{kg}\right.$ and $\mathrm{H}_{\mathrm{c}, \alpha}=$ 14.35 MJ/kg) were used for most thermal parameters, and the remaining parameters were estimated (Table 7). In the second model, all thermal parameters were estimated with GA (Table 8).

Table 7

Table 8

Thermal conductivity and specific heat were specified or estimated at three temperatures and interpolated from these values in the simulations. Comparing the values of the three fully estimated models (Table 8) we can observe that the estimated room-temperature values of thermal conductivity are within $15 \%$ of the 
measured value. At higher temperatures, where the measured values for thermal conductivity were not available, even factor of two differences are found between the different estimates. In case of specific heat, the estimated values are $25 \ldots 50 \%$ higher than the measured ones at room temperature, and $38 \ldots 87 \%$ higher at elevated temperatures. The estimated values of emissivity are 1.0 for the simple model and the cellulose-hemicellulose component of the Broido scheme, and 0.95 for the Grønli schemes. These values can be compared to the measurements of Chaos (2014) for a hardwood pallet material, indicating that the spectral emissivities of the virgin wood depend on the wavelength, varying between 0.1 and 0.95 the nearinfrared region. For char, the emissivities are much more constant, around 0.85 . It is important to notice that as the estimation process considers the entire test duration, the char values play a much more important role for the overall burning rate predictions; virgin wood emissivity mainly affecting the ignition time.

The experimental and simulated mass loss and heat release rates are plotted in Figure 6. All the models reproduce the main characteristics of the MLR and HRR curves, including the ignition and burn-out times, the burning rate reduction due to the formation of insulating char layer, and the second peak in the end. Some quantitative discrepancies can still be pointed out: (1) The models with fully estimated thermal parameters (GA) seem to fit more accurately to the ignition time and the first half of the experiment. (2) Models with measured parameters predict the time of the second peak too early and earlier than the fitted models. (3) All the models over-predict the early mass loss rate, which in our opinion is caused by inaccuracy of the physical models because the kinetics were accurately reproduced and the thermal parameters either measured or optimized. Consideration of the volatiles mass transfer and the anisotropic permeability might improve the predictions in this respect. (4) The heat of combustion, determined from MCC experiment (complete combustion), is not fully consistent with the bench scale combustion behaviour since an accurate MLR prediction seems to produce over-predicted HRR in most cases. (5) The differences between the models are greatest in the end of the burn, but since the scattering within the experimental data is also high in this part of the test, the models cannot be ranked according to their performance during the final stages of burning. (5) The modified Grønli model with estimated parameters seems to over-predict the 
HRR for whole test duration. This can be due to the different mass losses in the three experiments (cone calorimeter $<$ TGA $<$ MCC).
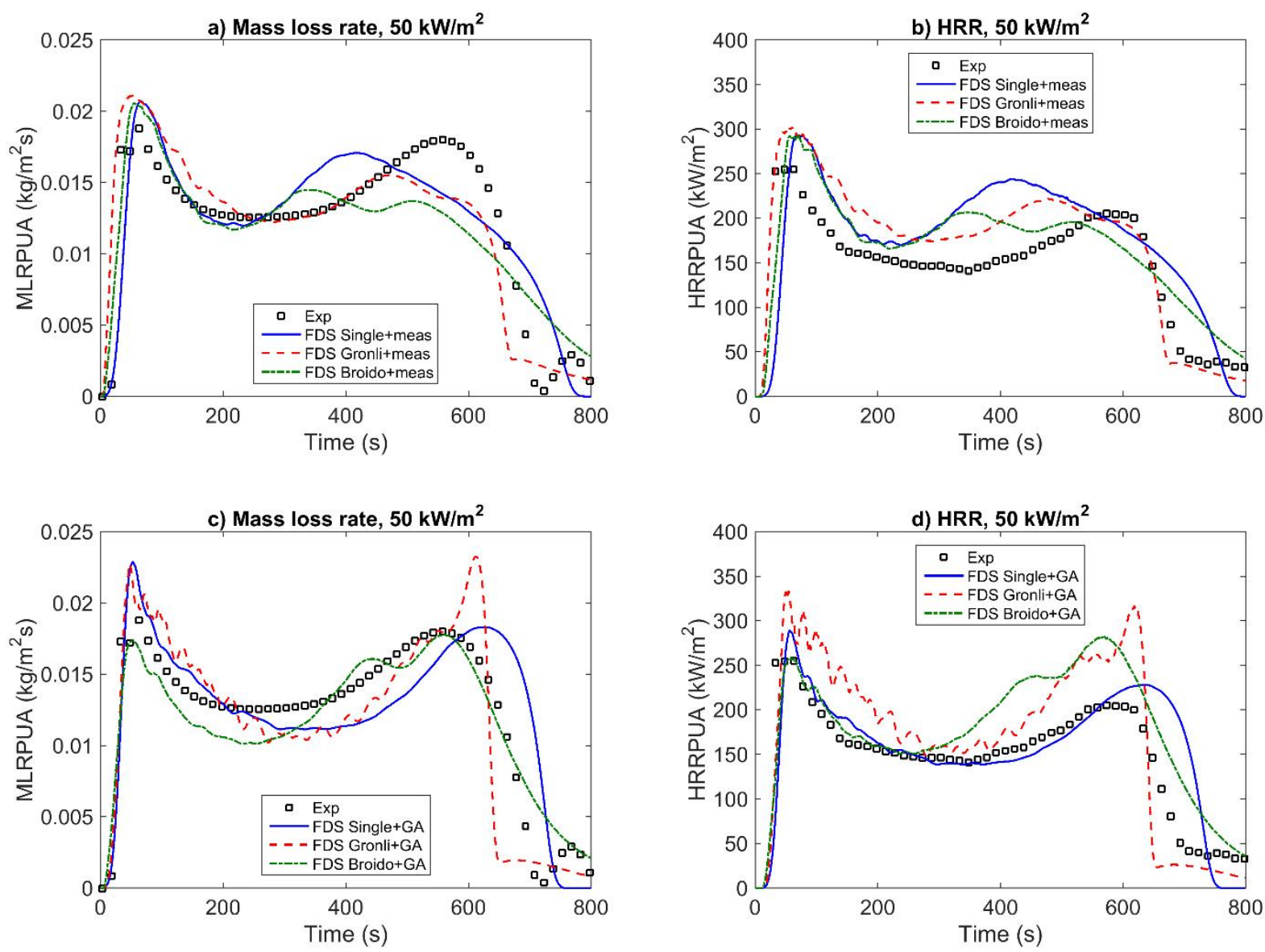

Figure 6. Experimental and simulated cone calorimeter results for $50 \mathrm{kW/ \textrm {m } ^ { 2 }}$ heat flux. Mass loss rate per unit area (MLRPUA) on the left, and heat release rate per unit area (HRRPUA) on the right. Figures $a$ and $b$ have measured properties, $c$ and d estimated.

Overall, the single reaction model with free parameters shows equal or even better performance in reproducing the experimental HRR than the modified Grønli or Broido schemes because the heat of combustion for this model was among the optimized parameters. The estimated $H_{\mathrm{c}}$ for the single reaction scheme is within $2.5 \%$ from the experimental value. 
Preprint, to appear in Combustion Science and Technology, 2017

\section{Model validation}

The models were validated using the cone calorimeter HRR at $35 \mathrm{~kW} / \mathrm{m}^{2}$ and $75 \mathrm{~kW} / \mathrm{m}^{2}$ heat fluxes. Unlike the dry samples used for parameter estimation, the validation samples contained moisture $10 \pm 1 \%$ of the wet mass.
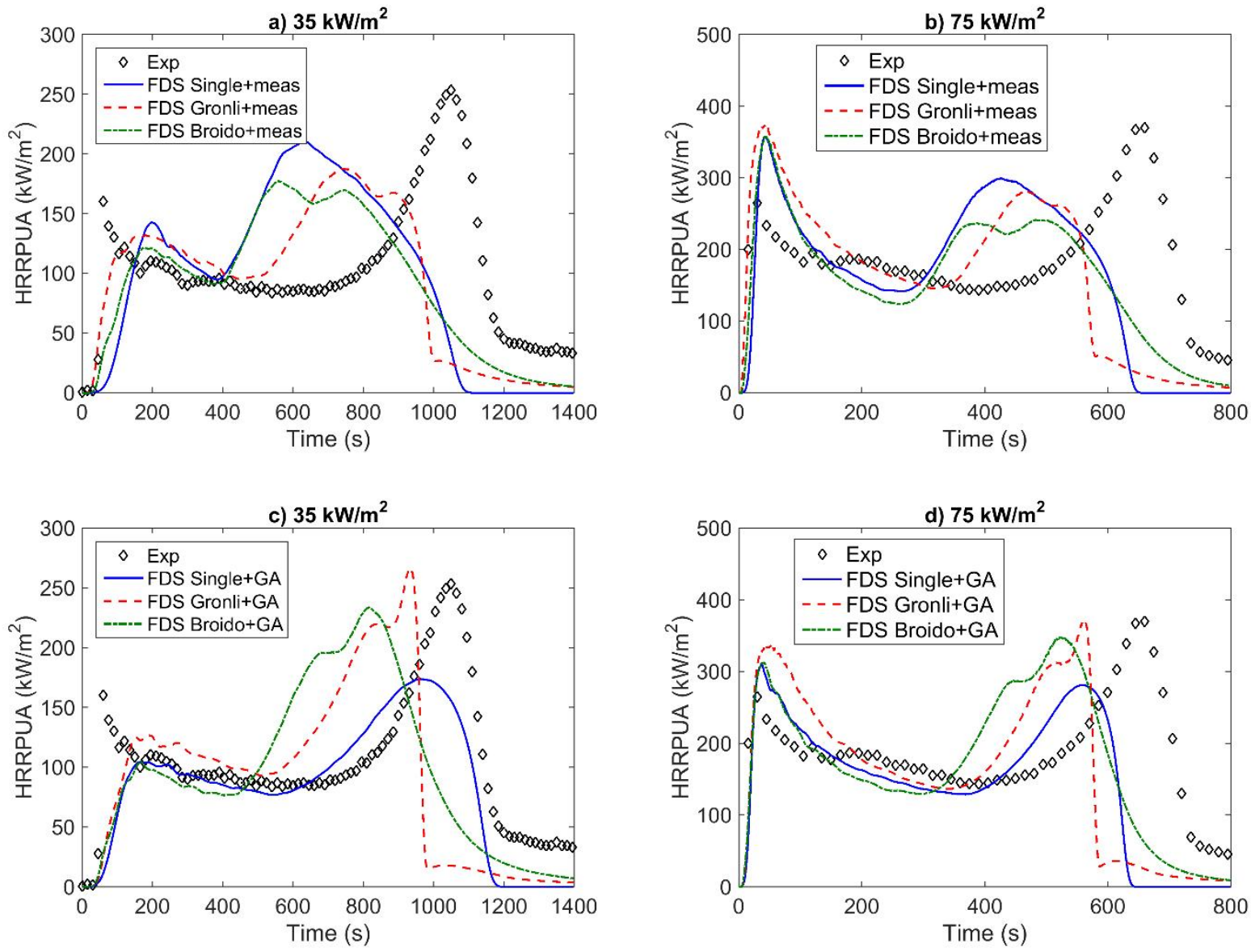

Figure 7. Validation of the HRR predictions at $35 \mathrm{~kW} / \mathrm{m}^{2}$ (left) and $75 \mathrm{~kW} / \mathrm{m}^{2}$ heat fluxes. Measured parameters on the top row, estimated on the second row.

Experimental and predicted heat release rates are compared in Figure 7. Of the models with measured properties (Figures $7 \mathrm{a}$ and $7 \mathrm{~b}$ ), the modified Grønli scheme most accurately captures the moment of ignition. At $35 \mathrm{~kW} / \mathrm{m}^{2}$ heat flux, all the models predict too slow growth HRR and slightly too low first peak, but the HRR levels after the ignition are correctly predicted. At $75 \mathrm{~kW} / \mathrm{m}^{2}$ heat flux, the height of the first 
Preprint, to appear in Combustion Science and Technology, 2017

peak is over-predicted. The time of the second peak is predicted too early by all the models with measured properties, regardless of the heat flux level. Overall, it seems that the modified Grønli scheme produces the best results when the thermal properties are mostly based on measured values, but the differences between the models are small.

Figures $7 \mathrm{c}$ and $7 \mathrm{~d}$ show the results for the models with all thermal parameters estimated from the $50 \mathrm{~kW} / \mathrm{m}^{2}$ cone calorimeter test. The ignition times and growth rates of the different models are now very close to each other, but the under-prediction of the low heat flux -growth rate and the over-prediction of the high heat flux peak HRR still remain. Overall HRR levels after the ignition are well predicted, but the final peaks appear too early. In comparison to the measured parameters, the times of the second HRR peak have transferred to later stage, closer to the experimental data. The experimental tail of the HRR curves represents the glowing oxidation of the char layer. As the oxidation reactions were not included in the reaction schemes, all the models fail to reproduce it. The oxidation most likely also contributes to the height of the second peak. The Single-step reaction scheme seems to produce most accurate predictions when the thermal properties were fitted to the cone calorimeter data.

\section{Conclusions}

The numerical modelling procedure for the simulation of burning hardwood has been presented, focusing on the verification of the experimentally determined material parameters and the validation of the models utilizing three different reaction schemes. The material modelling included the selection of the reaction schemes and the estimation of kinetic and thermal parameters. The sequential modelling procedure, where the material characterization tests are reproduced numerically, can ensure the correct interpretation of experimental data in the input parameter estimation.

Regarding the reaction schemes for thermal decomposition, the modified Grønli scheme was found to reproduce very well the experimentally observed mass loss rates in TGA. The first-order single-step scheme 
Preprint, to appear in Combustion Science and Technology, 2017

captured the main mass loss peak, slightly exaggerating the heating rate effect, but failed to initiate the pyrolysis at the correct temperature. The modified Broido-Shafizadeh scheme was shown to reproduce the shoulder-peak form of the DTG curve better than the single-step model, but the overall quantitative agreement was not as good as with the modified Grønli scheme.

Two sets of thermal parameters were tested for each of the three reaction schemes: One set with completely estimated values, and another with mostly measured values. The estimated values provided better fit both in the very beginning of the experiment and during the second peak of the mass loss and heat release rate curves, but the differences were not significant. This indicates that the thermal parameters of the pyrolysis models can be obtained by either measurement or by inverse methods without a significant difference in their predictive capability. With estimated properties, the single-step scheme was found to provide most robust and consistent predictions for the HRR.

The unambiguity of the pyrolysis model schemes or parameters was recently discussed by Bal and Rein (2015). They demonstrated the role of multiple compensation effects between the mechanisms and concluded that the model should be kept as simple as possible unless further research is able to identify a justification for added complexity. Our results support this conclusion.

\section{Acknowledgements}

We would like to acknowledge Dr. Johan Mangs of VTT for his help and advice in the experimental work. Thanks to Mr. Konsta Taimisalo (VTT), Mrs. Lea Räsänen (VTT), Dr. Tuula Leskelä (Aalto) and Prof. Michael Gasik (Aalto) for their help in conducting the cone calorimeter, DSC, TGA and hot-disk experiments, respectively. The continuous support from the FDS development team (Dr Kevin McGrattan, Dr Randall McDermott and Dr Glen Forney of NIST, Dr Jason Floyd of Jensen Hughes Inc.) is greatly appreciated. This work has been partially funded by the State Nuclear Waste Management Fund of Finland in the scope of the SAFIR-programmes and the Academy of Finland under grant 297030. 


\section{References}

Atreya, A. 1983. Pyrolysis, ignition and fire spread on horizontal surfaces of wood. Ph.D. Thesis, Harvard University. 440 p.

Baroudi, D. 1993. Piecewise least squares fitting technique using finite interval method with Hermite polynomials. VTT Technical Research Centre of Finland, Espoo. VTT Publications, 135, 27 p.

Chaos, M., Khan, M.M., Krishnamoorthy, N., de Ris, J.L., and Dorofeev, S.B. 2011. Evaluation of optimization schemes and determination of solid fuel properties for CFD fire models using bench-scale pyrolysis tests. Proc. Combust. Inst., 33, 2599-2606. doi:10.1016/j.proci.2010.07.018

Chaos, M. 2014Spectral Aspects of Bench-Scale Flammability Testing: Application to Hardwood Pyrolysis. Fire Safety Science, 11, 165-178.

Di Blasi, C. 1998. Physico-chemical processes occurring inside a degrading two-dimensional anisotropic porous medium. Int. J. Heat and Mass Trasfer, 41, 4139-4150.

Di Blasi, C. 2008. Modeling chemical and physical processes of wood and biomass pyrolysis, Progress in Energy and Combustion Sciences, 34, 47-90.

Ding, Y., Wang, C., Chaos, M., Chen, R, Lu, S. 2016. Estimation of beech pyrolysis kinetic parameters by Shuffled Complex Evolution, Bioresource Technology, 200, 658-665. doi: dx.doi.org/10.1016/j.biortech.2015.10.082

Friedman, H. L. 1964. Kinetics of thermal degradation of char-forming plastics from thermogravimetry. Application to a phenolic plastic. J. Polym. Sci., C Polym. symp., 6, 183-195. doi: 10.1002/polc.5070060121

Grønli, M.G., Varhegyi, G., and Di Blasi, C. 2002. Thermogravimetric analysis and devolatilization kinetics of wood. Ind. Eng. Chem. Res., 41, 4201-4208.

Harada, T., Hata, T., and Ishihara, S. 1998. Thermal constants of wood during the heating process measured with the laser flash method. J. Wood Sci., 44:6, 425-431. doi: 10.1007/BF00833405

Hankalin, V., Ahonen, T., and Raiko, R. 2009. On thermal properties of a pyrolysing wood particle. Proc. Finnish-Swedish Flame Days, 28.-29.1.2009, Naantali, Finland.

Kung, H.-C. 1972 A Mathematical Model of Wood Pyrolysis. Combust. Flame, 18, 185-195. doi:10.1016/S0010-2180(72)80134-2

Kung, H.-C. and Kalelkar, A.S. 1973. On the Heat of Reaction of Wood Pyrolysis. Combust. Flame 20, 91-103. doi:10.1016/S0010-2180(73)81260-X 
Lautenberger, C., and Fernandez-Pello, C. 2009. A model for the oxidative pyrolysis of wood. Combust. Flame, 156, 1503-1513. doi:10.1016/j.combustflame.2009.04.001

Lautenberger, C., Rein, G., and Fernandez-Pello, C. 2006. The application of a genetic algorithm to estimate material properties for fire modeling from bench-scale fire test data. Fire Safety J., 41, 204214. doi:10.1016/j.firesaf.2005.12.004

Li, K.-Y., Huang, X., Fleischmann, C., Rein, G., Jie, J. 2014. Pyrolysis of Medium-Density Fiberboard: Optimized Search for Kinetics Scheme and Parameters via a Genetic Algorithm Driven by Kissinger's Method. Energy and Fuels, 28 (9), 6130-6139.

Log, T., and Gustafsson, S.E. 1995. Transient plane source (TPS) technique for measuring thermal transport properties of building materials. Fire and Materials, 19, 43-49.

Luostarinen, K., and Verkasalo, E. 2000. Birch as sawn Timber and in mechanical further processing in Finland. A literature study. Silva Fennica Monographs 1. The Finnish Society of Forest Science. The Finnish Forest Research Institute. 2000. 40 p.

Lyon, R.E., and Walters, R.N. 2004. Pyrolysis combustion flow calorimetry. J. Analytical Applied Pyrolysis, 71(1), 27-46.

Lyon, R.E., Safronava, N., and Oztekin, E. 2011. A Simple method for Determining kinetic parameters for materials in fire models. Fire Safety Science, 10, 765-778, doi:10.3801/IAFSS.FSS.10-765.

Matala, A. 2013. Methods and applications of pyrolysis modelling for polymeric materials. VTT Science, 44 (Aalto University, dissertation).

McGrattan, K., Hostikka, S., McDermott, R., Floyd, J., Weinschenk, C., and Overholt, C. 2015. Fire Dynamics Simulator User's Guide. NIST Special Publication 1019. $6^{\text {th }}$ Edition.

McGrattan, K.B., McDermott, R., Floyd, J., Hostikka, S., Forney, G., and Baum, H. 2012. Computational fluid dynamics modelling of fire. Int. J. Comp. Fluid Dynamics, 1-13.

Parker, W.J., 1986. Prediction Of The Heat Release Rate Of Wood. Fire Safety Science, 1, 207-216. doi:10.3801/IAFSS.FSS.1-207

Parker, W.J. 1989. Prediction Of The Heat Release Rate Of Douglas Fir. Fire Safety Science, 2, 337346. doi:10.3801/IAFSS.FSS.2-337

Rath, J., Wolfinger, M.G., Steiner, G., Krammer, G., Barontini, F., Cozzani, V. 2003. Heat of wood pyrolysis. Fuel, 82, 81-91. doi:10.1016/S0016-2361(02)00138-2 
Simpson, W., and TenWolde, A. 1999. Physical Properties and Moisture Relations of Wood. Chapter 3 in Forest Products Laboratory. Wood handbook - Wood as an engineering material. Madison, WI, USA. 463 p.

Stengseng, M., Jensen, A., Dam-Johansen, K. 2001. Investigation of biomass pyrolysis by thermogravimetric analysis and differential scanning calorimetry. J. Analytical and Applied Pyrolysis, 58-59, 765-780.

Stoliarov, S.I., Crowley, S., Walters, R.N., and Lyon, R.E. 2010. Prediction of the burning rates of charring polymers. Combustion and Flame, 154, 2024-2034.

doi:10.1016/j.combustflame.2010.03.011

Suleiman, B.M., Larfield, J., Leckner, B., and Gustavsson, M. 1999. Thermal conductivity and diffusivity of wood. Wood Sci. Tech., 33 (6), 465-473.

Wichman, I.S. and Atreya, A. 1987. A Simplified Model for the Pyrolysis of Charring Materials. Combust. Flame 68, 231-247. doi:10.1016/0010-2180(87)90002-2

Bal, N. and Rein, G. 2013. Relevant model complexity for non-charring polymer pyrolysis. Fire Safety Journal 61: 36-44.

Bal, N. and Rein, G. 2015. On the effect of inverse modelling and compensation effects n computational pyrolysis for fire scenarios. Fire Safety Journal 72: 68-76. 
Preprint, to appear in Combustion Science and Technology, 2017

\section{Figure captions}

Figure 1. Reaction schemes.

Figure 2. TGA (left column) and DTG (right column) results for experiments (solid lines) and simulations (dashed lines) with single-step scheme (a-b), modified Gronli scheme ( $c$-d), and modified Broido-Shafizadeh scheme (e-f).

Figure 3. TGA mass loss rates for birch, wood primary components and a weighted sum of the components.

Figure 4. DSC measurement and simulation of the reaction enthalpy for birch pyrolysis. Exothermic direction is upwards.

Figure 5. MCC results of birch at $33 \mathrm{~K} / \mathrm{min}$ (left) and $85 \mathrm{~K} / \mathrm{min}$ (right) heating rates. Experimental data with circles and simulated with lines. See text for the explanation of simulations.

Figure 6. Experimental and simulated cone calorimeter results. Mass loss rate per unit area (MLRPUA) on the left, and heat release rate per unit area (HRRPUA) on the right. Figures $a$ and $b$ have measured properties, $c$ and d estimated.

Figure 7. Validation of the HRR predictions at $35 \mathrm{~kW} / \mathrm{m}^{2}$ (left) and $75 \mathrm{~kW} / \mathrm{m}^{2}$ heat fluxes. Measured parameters on the top row, estimated on the second row. 
Preprint, to appear in Combustion Science and Technology, 2017

Table 1. Commercially extracted wood constituents of this work and their assumed mass fractions in birch (Luostarinen and Verkasalo, 2000).

\begin{tabular}{|l|l|l|}
\hline & Product name & Mass fraction in dry birch (\%) \\
\hline Cellulose & Avicel PH-101 cellulose & 50.9 \\
\hline Hemicellulose & Xylan from birch wood & 25.4 \\
\hline Lignin & Lignin (alkali) & 23.4 \\
\hline
\end{tabular}


Preprint, to appear in Combustion Science and Technology, 2017

Table 2. TGA test results for the $\mathrm{N}_{2}$ atmosphere and the corresponding model parameters for the single first-order reaction model.

\begin{tabular}{|l|l|l|l|l|l|l|}
\hline Heating rate & $Y_{\mathrm{s}, \alpha}(0)$ & $v_{\text {char }}$ & Peak MLR & $T_{\mathrm{p}}$ & $A_{\alpha \beta}$ & $\left(\mathrm{m}^{-1}\right.$ \\
$(-)$ & $(-)$ & $\left(\mathrm{s}^{-1}\right)$ & $\left(\mathrm{s}^{-1}\right)$ & $\begin{array}{l}E_{\alpha \beta} \\
\left(\mathrm{kJ} \cdot \mathrm{mol}^{-1}\right)\end{array}$ \\
\hline 2 & 0.973 & 0.175 & $4.99 \times 10^{-4}$ & 344 & $2.24 \times 10^{8}$ & 132 \\
\hline 5 & 0.964 & 0.151 & $1.19 \times 10^{-3}$ & 358 & $3.72 \times 10^{8}$ & 133 \\
\hline 10 & 0.974 & 0.164 & $2.04 \times 10^{-3}$ & 370 & $2.00 \times 10^{7}$ & 118 \\
\hline 20 & 0.984 & 0.168 & $3.71 \times 10^{-3}$ & 381 & $5.53 \times 10^{6}$ & 109 \\
\hline Average & & 0.164 & & & $5.58 \times 10^{7}$ & 123 \\
\hline
\end{tabular}


Preprint, to appear in Combustion Science and Technology, 2017

Table 3. Reaction parameters and estimation boundaries for the modified Gronli reaction path.

\begin{tabular}{|l|c|c|c|c|c|}
\hline \multirow{2}{*}{} & & \multicolumn{4}{|c|}{ Parameter value } \\
& & \multicolumn{4}{|c|}{ (estimation bounds) } \\
\hline & $Y_{\mathrm{s}, \alpha}(0)$ & $A_{\alpha \beta}$ & $E_{\alpha \beta}$ & $n_{\alpha \beta}$ & $v_{\text {gas }}$ \\
& $(-)$ & $\left(\mathrm{s}^{-1}\right)$ & $\mathrm{kJ} \cdot \mathrm{mol}^{-1}$ & $(-)$ & $(-)$ \\
\hline \multirow{2}{*}{ cellulose } & 0.495 & $3.77 \times 10^{11}$ & 168 & 0.471 & 0.97 \\
& & $\left(10^{5}-10^{15}\right)$ & $(100-200)$ & $0.1-2$ & $0.85-0.98$ \\
\hline \multirow{2}{*}{ hemicellulose } & 0.247 & $5.48 \times 10^{11}$ & 147 & 1.50 & 0.95 \\
& & $\left(10^{5}-10^{12}\right)$ & $(80-200)$ & $(1-3)$ & $(0.7-1.0)$ \\
\hline \multirow{2}{*}{ lignin } & 0.227 & $1.18 \times 10^{10}$ & 158 & 6.67 & 0.46 \\
& & $\left(10^{5}-10^{12}\right)$ & $(100-300)$ & $(2-8)$ & $(0.45-0.6)$ \\
\hline \multirow{2}{*}{ water } & 0.029 & $9.57 \times 10^{22}$ & 136 & 3.31 & $(1-4)$ \\
& & $\left(10^{20}-10^{25}\right)$ & $(100-200)$ & $($ fixed $)$ \\
\hline
\end{tabular}


Preprint, to appear in Combustion Science and Technology, 2017

Table 4. Kinetic parameters for the modified Broido-Shafizadeh reaction scheme.

\begin{tabular}{|l|c|c|c|c|c|c|}
\hline & & & \multicolumn{5}{|c|}{ estimated value } \\
& & & \multicolumn{4}{|c|}{ (estimation bounds $)$} \\
\hline & $Y_{\mathrm{s}, \alpha}(0)$ & & $A_{\alpha \beta}$ & $E_{\alpha \beta}$ & $n_{\alpha \beta}$ & $v_{\text {gas }}$ \\
& $(-)$ & & $\left(\mathrm{s}^{-1}\right)$ & $\left(\mathrm{kJ} \cdot \mathrm{mol}^{-1}\right)$ & $(-)$ & $(-)$ \\
\hline \multirow{2}{*}{ cellulose-hemicellulose } & \multirow{2}{*}{0.740} & & $\left(10^{8}-10^{12}\right)$ & $(100-200)$ & $0.1-4$ & $0.85-0.95$ \\
& & & $1.2 \times 10^{5}$ & 287 & 0.85 & 0 \\
\hline \multirow{2}{*}{ lignin } & & b) & $\left(10^{5}-10^{15}\right)$ & $(150-300)$ & $0.1-4$ & - \\
\hline \multirow{2}{*}{ water } & \multirow{2}{*}{0.234} & & $1.9 \times 10^{15}$ & 184 & 2.0 & 0.75 \\
& & & $\left(10^{5}-10^{20}\right)$ & $(100-200)$ & $(1.5-4)$ & $(0.4-0.6)$ \\
\hline
\end{tabular}


Preprint, to appear in Combustion Science and Technology, 2017

Table 5. Specific heats of the virgin birch and char.

\begin{tabular}{|l|l|l|l|}
\hline \multicolumn{2}{|c|}{ Virgin birch } & \multicolumn{2}{c|}{ Birch char } \\
\hline $\mathrm{T}\left({ }^{\circ} \mathrm{C}\right)$ & $c_{\mathrm{s}}\left(\mathrm{kJ} \cdot(\mathrm{kg} \cdot \mathrm{K})^{-1}\right)$ & $\mathrm{T}\left({ }^{\circ} \mathrm{C}\right)$ & $c_{\mathrm{s}}\left(\mathrm{kJ} \cdot(\mathrm{kg} \cdot \mathrm{K})^{-1}\right)$ \\
\hline 4 & 1.11 & 198 & 0.52 \\
\hline 20 & 1.20 & 234 & 0.76 \\
\hline 168 & 1.36 & 306 & 0.96 \\
\hline 196 & 1.40 & 378 & 1.03 \\
\hline 231 & 1.42 & 450 & 1.10 \\
\hline
\end{tabular}


Preprint, to appear in Combustion Science and Technology, 2017

Table 6. MCC results for dry wood as mean values and standard deviations (in parentheses) from three replicate tests. The uncertainty of the total heat of combustion per produced mass of gas is the combined uncertainty of sample mass and heat of combustion measurements.

\begin{tabular}{|c|c|c|c|c|c|}
\hline \multirow{3}{*}{$\begin{array}{c}\text { Nominal } \\
\text { heating rate } \\
\left(\mathrm{K} \cdot \mathrm{min}^{-1}\right)\end{array}$} & $\begin{array}{c}\text { True heating } \\
\text { rate }\end{array}$ & $\begin{array}{c}\text { Total mass loss } \\
\text { (\%) }\end{array}$ & \multicolumn{2}{|c|}{$\begin{array}{l}\text { Total heat of combustion } \\
\qquad\left(\mathrm{MJ} \cdot \mathrm{kg}^{-1}\right)\end{array}$} & \multirow{3}{*}{$\begin{array}{c}\text { Peak } \\
\text { temperature } \\
\left({ }^{\circ} \mathrm{C}\right)\end{array}$} \\
\hline & $(\mathrm{K} \cdot \mathrm{mm})$ & & & & \\
\hline & & & $\begin{array}{c}\text { per sample } \\
\text { mass }\end{array}$ & $\begin{array}{l}\text { per produced } \\
\text { mass of gas }\end{array}$ & \\
\hline 20 & 33 & $87.7(1.3)$ & $12.5(0.2)$ & $14.1 \pm 0.3$ & $358(1.6)$ \\
\hline 60 & 85 & 86.5 (1.3) & $12.8(0.4)$ & $14.6 \pm 0.5$ & $370(2.4)$ \\
\hline
\end{tabular}


Preprint, to appear in Combustion Science and Technology, 2017

Table 7. Estimated thermal parameters supplementing the measured parameters of birch or its components $(C-c e l l u l o s e, H C-$ hemicellulose, L-lignin).

\begin{tabular}{|c|c|c|c|c|}
\hline & $\begin{array}{c}\text { Temperature } \\
\left({ }^{\circ} \mathrm{C}\right)\end{array}$ & $\begin{array}{c}\text { Single-step } \\
\text { scheme }\end{array}$ & $\begin{array}{c}\text { Grønli scheme } \\
\text { (C / HC / L) }\end{array}$ & $\begin{array}{c}\text { Broido } \\
(\mathrm{C} \& \mathrm{HC} / \mathrm{L})\end{array}$ \\
\hline \multicolumn{5}{|c|}{ Wood } \\
\hline \multirow{2}{*}{$k_{\mathrm{s}}\left(\mathrm{W} \cdot(\mathrm{m} \cdot \mathrm{K})^{-1}\right)$} & 300 & 0.5 & 0.23 & 0.5 \\
\hline & 600 & 0.6 & 0.25 & 1.2 \\
\hline$c_{\mathrm{s}}\left(\mathrm{kJ} \cdot(\mathrm{kg} \cdot \mathrm{K})^{-1}\right)$ & 600 & 1.5 & 1.5 & 1.45 \\
\hline$\varepsilon(-)$ & & & $1.0 / 1.0 / 0.8$ & $0.95 / 0.95$ \\
\hline \multicolumn{5}{|c|}{ Residue } \\
\hline$\rho_{\mathrm{s}}\left(\mathrm{kg} \cdot \mathrm{m}^{-3}\right)$ & & 380 & 300 & 250 \\
\hline$k_{\mathrm{s}}\left(\mathrm{W} \cdot(\mathrm{m} \cdot \mathrm{K})^{-1}\right)$ & & 0.1 & 0.1 & 0.1 \\
\hline$\varepsilon(-)$ & & 1.0 & 1.0 & 1.0 \\
\hline
\end{tabular}


Preprint, to appear in Combustion Science and Technology, 2017

Table 8. Estimated thermal parameters of birch or its components ( $\mathrm{C}$ - cellulose, $\mathrm{HC}-$ hemicellulose, $\mathrm{L}-$ lignin).

\begin{tabular}{|c|c|c|c|c|}
\hline & $\begin{array}{c}\text { Temperature } \\
\left({ }^{\circ} \mathrm{C}\right)\end{array}$ & $\begin{array}{c}\text { Single-step } \\
\text { scheme }\end{array}$ & $\begin{array}{c}\text { Grønli scheme } \\
\text { (C / HC / L) }\end{array}$ & $\begin{array}{l}\text { Broido scheme } \\
\text { (C\&HC / L) }\end{array}$ \\
\hline \multicolumn{5}{|c|}{ Wood } \\
\hline$\rho_{\mathrm{s}}\left(\mathrm{kg} \cdot \mathrm{m}^{-3}\right)$ & & 600 & 600 & 600 \\
\hline \multirow{3}{*}{$k_{\mathrm{s}}\left(\mathrm{W} \cdot(\mathrm{m} \cdot \mathrm{K})^{-1}\right)$} & 20 & 0.20 & 0.24 & 0.3 \\
\hline & 300 & 0.25 & 0.3 & 0.4 \\
\hline & 600 & 0.30 & 0.5 & 0.5 \\
\hline \multirow{3}{*}{$c_{\mathrm{s}}\left(\mathrm{kJ} \cdot(\mathrm{kg} \cdot \mathrm{K})^{-1}\right)$} & 20 & 1.5 & 1.8 & 1.6 \\
\hline & 300 & 2.0 & 2.5 & 2.0 \\
\hline & 600 & 2.1 & 2.8 & 2.1 \\
\hline$\varepsilon(-)$ & & 1.0 & 0.95 & $1.0 / 0.95$ \\
\hline$H_{\mathrm{r}, \alpha}\left(\mathrm{kJ} \cdot \mathrm{kg}^{-1}\right)$ & & 300 & $100 / 400 / 300$ & $100 / 100$ \\
\hline$H_{\mathrm{c}, \alpha}\left(\mathrm{MJ} \cdot \mathrm{kg}^{-1}\right)$ & & 12.5 & $13.5 / 17.0 / 13.4$ & $16 / 12$ \\
\hline \multicolumn{5}{|c|}{ Residue } \\
\hline$\rho_{\mathrm{s}}\left(\mathrm{kg} \cdot \mathrm{m}^{-3}\right)$ & & 120 & 100 & $120 / 100$ \\
\hline$k_{\mathrm{s}}\left(\mathrm{W} \cdot(\mathrm{m} \cdot \mathrm{K})^{-1}\right)$ & & 0.55 & 0.20 & $0.35 / 1.0$ \\
\hline$\overline{c_{\mathrm{s}}\left(\mathrm{kJ} \cdot(\mathrm{kg} \cdot \mathrm{K})^{-1}\right)}$ & & 2.5 & 1.5 & $1.0 / 1.0$ \\
\hline
\end{tabular}

